\title{
Tracing the antibody mediated acquired immunity by Foot and Mouth disease and Rift Valley Fever combined vaccine in pregnant ewes and their lambs
}

\author{
Wael Mossad Gamal' Eman Mahmoud Mohamed Soliman² and Mona Ali El-Manzalawy³
}

1. Department of Foot and Mouth disease, Veterinary Serum and Vaccine Research Institute, Abbasia, Cairo, Egypt;

2. Department of reference strain bank, Central Laboratory for Evaluation of Veterinary Biologics, Cairo, Egypt;

3. Department of Rift Valley Fever, Veterinary Serum and Vaccine Research Institute, Abbasia, Cairo, Egypt.

Corresponding author: Wael Mossad Gamal, e-mail: waelmossad@gmail.com,

EMMS: emansoliman80@gmail.com, MAE: elmanzalawy1970@gmail.com

Received: 15-07-2014, Revised: 19-09-2014, Accepted: 26-09-2014, Published online: 07-11-2014

doi: 10.14202/vetworld.2014.922-928. How to cite this article: Gamal WM, Soliman EMM, El-Manzalawy MA (2014) Tracing the antibody mediated acquired immunity by foot and mouth disease and rift valley fever combined vaccine in pregnant ewes and their lambs, Veterinary World 7(11): 922-928.

\begin{abstract}
Aim: The aim of this study is to provide adequate protection to ewes and their lambs against Foot and Mouth disease (FMD) and Rift Valley Fever (RVF).

Materials and Methods: A combined inactivated FMD and RVF oil vaccine was prepared successfully. Such vaccine was found to be free from foreign contaminants, safe and potent as determined by quality control tests such as challenge protection percentage for FMD and mice $\mathrm{ED}_{50}$ for RVF. Vaccination of pregnant ewes with the prepared combined vaccine and determination of the antibody level via serum neutralization test (SNT) and Enzyme Linked immune sorbent assay (ELISA) in the vaccinated pregnant ewes and their lambs.

Results: Vaccination of pregnant ewes revealed that these ewes exhibited high levels of specific antibodies against the included vaccine antigens (Foot and Mouth disease virus type A Iran O5, O PanAsia and SAT2/EGY/2012 and RVFV-ZH501). FMD antibodies recorded their peaks by the $10^{\text {th }}$ week post vaccination while those of RVF recorded their peaks by the $12^{\text {th }}$ week post vaccination then all antibodies began to decrease gradually to reach their lowest protective titers for FMD by the $32^{\text {nd }}$ week post vaccination and those for RVF by the $34^{\text {th }}$ week post vaccination. Potency test of the prepared combined vaccine expressed as protection percentage of vaccinated sheep against target virulent FMD virus serotypes reflected a

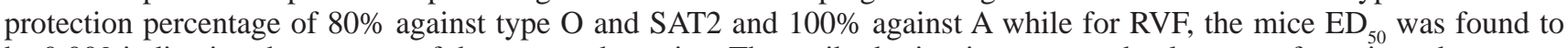
be 0.009 indicating the potency of the prepared vaccine. The antibody titer in serum and colostrum of vaccinated pregnant ewes at day of parturition (10-12 week post vaccination) recorded a high titer against FMD serotype (O), serotype (A), serotype (SAT2) and against RVF. It was noticed that the colostrum antibody titers were slightly higher than those in the sera of vaccinated ewes at time of parturition. The newly born lambs from vaccinated ewes, exhibited good levels of maternal immunity against the included antigens through suckling their mother colostrum by the 24 hrs. post parturition. The newly born lambs recorded their highest level by 1 week of birth and lasted within a protective level up to 11-12 week of birth.
\end{abstract}

Conclusion: Using of FMD/RVF combined vaccine provided a sufficient immune status for pregnant ewes as well as for their lambs. Vaccination of newly born lambs should be carried out by the $4^{\text {th }}$ month of birth.

Keywords: FMD, RVF, combined vaccine, pregnant ewes, new born lambs, SNT, ELISA.

\section{I ntroduction}

Foot and mouth disease (FMD) is a highly infectious disease of cloven footed animals including cattle, sheep, goats, pigs and also wild animals. Foot and mouth disease virus (FMDV) is the main etiologic agent of the disease which causes an acute disease characterized by fever, lameness and vesicular lesions on the feet, tongue, snout and teats, with high morbidity and low mortality [1].

The etiological agent, FMDV belongs to genus: Aphthovirus, family: Picornaviridae. The virus exists in the form of seven serologically and genetically distinguishable types, namely, O, A, C, Asia1, SAT1, SAT2, and SAT3, also a large number of subtypes have evolved within each serotype [2]. In Egypt, the

Copyright: The authors. This article is an open access article licensed under the terms of the Creative Commons Attributin License (http:// creative commons.org/licenses/by/2.0) which permits unrestricted use, distribution and reproduction in any medium, provided the work is properly cited. disease is enzootic and many outbreaks have been reported since 1950. FMD serotypes SAT2, A and O were last reported in years 1950, 1972 and 2000 respectively [3]. The type $\mathrm{O}$ was the most prevalent since 1960 and onwards [4,5]. Serotype A was reintroduced to Egypt during 2006 through live animal's importation where sever clinical signs were recorded among cattle and buffaloes [6]. In addition, serotype SAT2 of FMD virus was later introduced to Egypt during 2012 also through live animal's importation [7]. Live animals importation is considered as a main risk factor in many old and new outbreaks in Egypt.

Control of FMD in animals was considered to be the corner stone to eliminate the disease in endemic areas through effective vaccination of susceptible animals [1], beside controlling the in and out motion of the live susceptible animals. 
Rift valley fever (RVF) is an acute viral disease that can cause severe disease in domestic animals as buffalo, camels, cattle, goats and sheep) and human. Disease in these species characterized by fever, severe illness, abortions, and a high morbidity and mortality rate. The etiologic cause is RVF virus (RVFV) which belongs to genus: Phlebovirus, family: Bunyaviridae $[8,9]$. The most significant economic losses of RVF is due to death in young animals and abortion among infected livestock [10].

Egypt is the most northern, and populous nation to have suffered from RVF and the human illness and death experienced there during the1977-1978 epizootic which was of unprecedented severity. In Egypt, RVF outbreaks had occurred in 1993, 1999, and most recently in 2003. In most cases these outbreaks were believed to have begun as epizootics among sheep, goats, cattle, and camels, which serve as amplifying hosts of the virus. The outbreaks of RVF in Upper Egypt during 1977 were preceded by epizootics that occurred to the south of Egypt in Sudan, Kenya, and Uganda, and were thought to result from the movement of herd animals into Egypt from the south $[11,12]$. The most common risk factor in Egypt between FMD and RVF is the movement of herd animals from another neighbor endemic areas.

Vaccine oil adjuvant is very important factor affecting the immune response and stimulate specific component either humeral or cell mediated immunity [13]. An oily vaccine was prepared by using Montanide oil as adjuvant to FMD, combined FMD with RVF and RVF vaccines giving high titer of antibodies and long duration of antibodies [14]. Furthermore, Montanide oil adjuvant for inactivated RVF vaccine induced early immune response in sheep rather than the alum gel [15]. As well as, it was sufficient to protect the animal all over the year with only one vaccine dose rather than the alum gel which needed $2^{\text {nd }}$ booster dose to maintain the protection all over the year.

A combined vaccine is that one consists of 2 or more separate immunogens physically combined into a single product [16]. Several benefits of a combined vaccine must be fulfilled as aiming to prevent multiple diseases caused by different organisms [17] and also reducing the number of injections and therefore the degree of pain and side effect of repeated vaccination. Also the result of this combination must be linked with the humeral immune response against the targeted organisms. The combined vaccine against FMD/RVF has been studied before and revealed an efficient humeral immune response against FMDV and RVFV in comparison with the single one [18].

The present study was intended to study the acquired maternal immunity induced by ISA206 oil FMD/RVF combined vaccine in new born lambs from vaccinated pregnant ewes so as to complete the scope of humeral immunity not only for ewes but also for their lambs and also to determine the most suitable time for the first immunization of the newly born lambs.

\section{Material and Methods}

\section{Ethical approval}

The experiment was carried out according to the protocol of Institutional Animal Ethics Committee and the authors had a permission of the animal owners at the private farms.

\section{Animals}

Sheep

Thirty-three native breed sheep were found to be serologically negative for the presence of antibodies against FMDV type A, O or SAT2 and antibodies against RVF as proved by SNT and ELISA. These animals were classified as demonstrated in Figure-1.

\section{New born lambs}

Fifteen lambs born to previously vaccinated and control ewes were used for determination of maternal derived immunity against FMDV type A, O or SAT2 and RVFV. These lambs suckled colostrum from their ewes immediately post parturition.

\section{Suckling baby mice}

Suckling Swiss baby mice, 2-4 days old, (Charles River Strain, USA) were used for the safety of the prepared vaccine.

\section{Weaned mice}

Swiss albino weaned mice; 21-28 days old supplied by the Laboratory Animal Breeding Unit, Veterinary Serum and Vaccine Research Institute, Abbasia, Cairo, Egypt were used for titration of the virus, testing the potency of the prepared vaccine for RVF via $\mathrm{ED}_{50}$.

\section{Samples}

\section{Serum samples}

- Serum samples were collected from pregnant ewes pre vaccination and weekly post vaccination for 10 weeks and then every 2 weeks up to 36 weeks post vaccination

- Serum samples collected from new born lambs weekly till 13 weeks after birth.

All the serum samples were tested for the presence of derived acquired maternal antibodies either against FMDV (A, O and SAT2) and RVFV using SNT and ELISA.

\section{Colostrum samples}

Colostrum samples were collected from ewes at the $24 \mathrm{~h}$ post parturition. These samples treated with renin and stored at $-20^{\circ} \mathrm{C}$ until detection of antibody titer against FMDV and RVFV by SNT and ELISA.

\section{Cell culture}

Baby Hamster kidney cell line (BHK21) Clone 13 obtained from Veterinary Serum and Vaccine Research Institute, Abbasia, Cairo using Eagl's medium with $8-10 \%$ bovine serum as described by Xuan et al. [19] used for application of SNT, virus titration and vaccine preparation. 


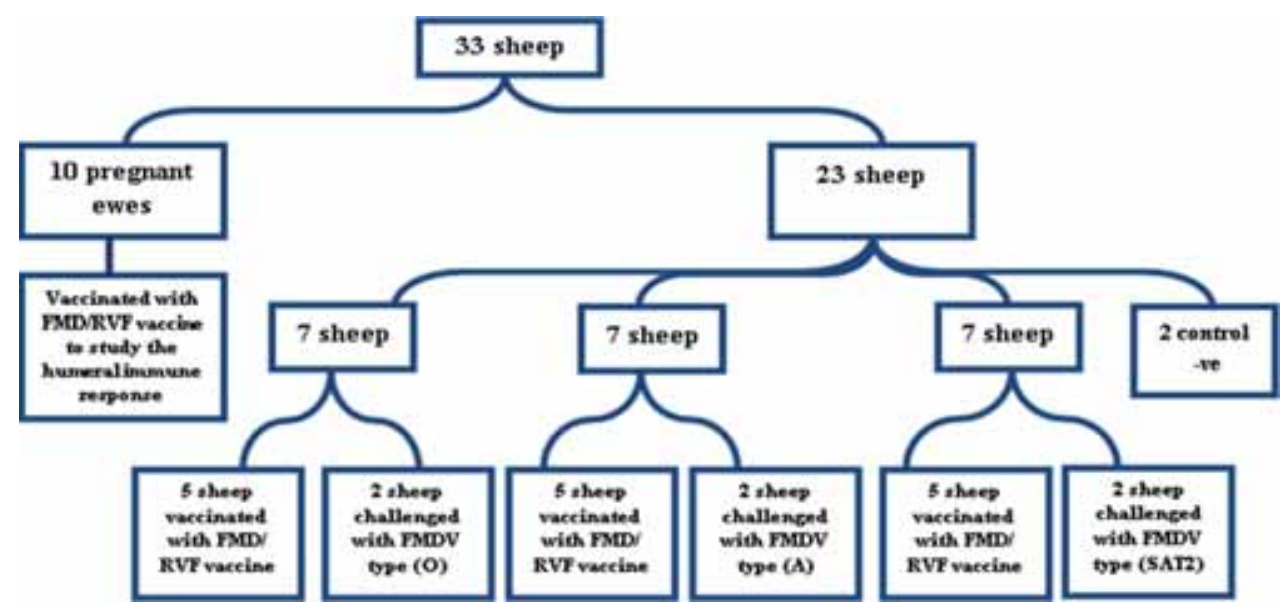

Figure-1: Classification of experimental sheep. *The combined vaccine was inoculated $\mathrm{S} / \mathrm{C}$ at a dose of $1 \mathrm{ml} / \mathrm{animal}$ inoculated. Each $1 \mathrm{ml}$ dose contain $10^{9}$ of the Foot and mouth disease virus serotype A, O, SAT2 and $10^{8.5} \mathrm{TCID}_{50}$ for the Rift Valley Fever. $* *$ The pregnant ewe were vaccinated with at 2-3 months before parturition.

\section{Viruses}

\section{FMD virus strains}

Local FMD virus type's O pan Asia, A Iran O5 and SAT2/EGY/2012 propagated in BHK21 cell line monolayer cultures were used for preparation of virus infected fluids and supplied by the Department of FMD Research, Veterinary Serum and Vaccine Research Institute. The titer of the three types was $9 \log _{10} \mathrm{TCID}_{50} / \mathrm{ml}$ as calculated by Reed and Muench [20] with CF value 1/64 detected according to [21].

\section{RVF virus (ZH 501)}

RVF virus was supplied by RVF Research Department, Veterinary Serum and Vaccine Research Institute, Abbasia Cairo with a titter $10^{8.5} \mathrm{TCID}_{50} / \mathrm{ml}$ following the techniques recommended by El-Nimr [22]. The antigen was stored at $-70^{\circ} \mathrm{C}$.

\section{Virus purification}

Aseptically, the harvested culture media from FMD and RVF virus infected BHK21 cell cultures were centrifuged in a cooling centrifuge at $3000 \mathrm{rpm}$ for $20 \mathrm{~min}$ to remove cell debris.

\section{Virus concentration}

The tissue culture viral fluids of the three serotypes of FMDV (O pan Asia-2, A Iran O5 and SAT2/EGY/2012) and RVFV were centrifuged at 7000 revolution/min for $30 \mathrm{~min}$ and then concentrated by PEG-6000 to reach to $1 / 10$ of its original volume [18].

\section{Virus inactivation}

$1 \% \mathrm{M}$ Binary ethylenamine (BEI) in $0.2 \mathrm{~N}$ $\mathrm{NaOH}$ was added to the virus suspension to give final concentration of $0.001 \mathrm{M}$ of BEI. The virus and BEI mixture were mixed well and the $\mathrm{pH}$ adjusted to 8.0 by sodium bicarbonate. The virus was placed on a magnetic stirrer in the incubator at $37^{\circ} \mathrm{C}$ for $18 \mathrm{~h}$ for inactivation. Sodium thiosulphate was added in a final concentration of $2 \%$ to neutralize the BEI action according to [23].
Formulation of FMD/RVF combined vaccine with Montanide ISA 206

The combined vaccine was prepared by mixing equal volumes of inactivated FMD virus strains and inactivated RVF virus. That aqueous antigen mixture was added in equal weight (w/w) to Montanide ISA 206 oil phase and mixed thoroughly [18].

\section{Evaluation of the prepared combined vaccine}

\section{Sterility test}

The prepared combined vaccine was tested for its freedom of aerobic and anaerobic bacteria, fungal and mycoplasma contaminants where vaccine samples were cultured on thioglycolate broth, Sabouraud's, Nutrient agar; phenol dextrose media and mycoplasma medium according to $[8,24]$.

\section{Safety test in baby mice}

Three to five days old Swiss Albino suckling mice were used for the safety test of inactivated FMD and RVF viruses according to [25].

\section{Potency test}

Determination of mice $\mathrm{ED}_{50}$ for RVF

Fivefold dilutions of the vaccine were prepared in suitable media starting from 1:1 to 1:625. Five groups of weaned mice (21-28 days old) were used for each dilution and each mouse was inoculated with two doses of $0.2 \mathrm{ml}$ of the vaccine I/P, 1 week a part. Seven days after the second inoculation, all animals were challenged via I/P route with $0.1 \mathrm{ml}$ of RVF virus containing $10^{3} \mathrm{MIPLD}_{50} / \mathrm{ml}$ in addition to other two groups of mice, one inoculated with challenge virus as positive control and one kept as non-vaccinated non challenged negative control. All groups of mice were kept under observation for 21 days and deaths were recorded daily. The $\mathrm{ED}_{50} / \mathrm{ml}$ was calculated according to the method of [20]. Deaths occurring during the $1^{\text {st }}$ day were considered as nonspecific.

Determination of challenge protection percentage in sheep against FMDV serotypes 
All vaccinated and control positive sheep were inoculated with the challenged FMDV either serotype A or O or SAT2 with titer $10^{4} \mathrm{BID}_{50}$ on the base of the tongue. All challenged animals were kept under daily observation and clinically examined for 1 week post infection, where lesions on the gum and oral mucosa as well as inter digital space were recorded. Control negative sheep were included in this experiment.

Evaluation of the humeral immune response to the prepared combined FMD and RVF vaccine in pregnant ewes and their newborn lambs

Serum samples collected from pregnant vaccinated ewes before and after parturition, newborn lambs from vaccinated ewes and colostrum samples from ewes at the $24 \mathrm{hrs}$. after parturition were tested for the presence of antibody titers against the three serotypes of FMDV (Opan Asia, A Iran O5 and SAT2/ EGY/2012) and RVFV by SNT using the technique described by $[25,26]$ and indirect ELISA according to Voller et al. [27].

\section{Results and Discussion}

Usually, the attention of vaccine researchers directed toward the vaccine evolution aiming to provide a maximum immunogenicity to livestock, especially against the most dangerous diseases like FMD and RVF. So, the present work succeed to prepare an inactivated combined FMD/RVF oil vaccine which found to be free from foreign contaminants; safe for vaccinated sheep and suckling mice and potent inducing adequate protection for vaccinated animals and their lambs coming in agreement with the earlier report [24].

It was confirmed that the prepared FMD/RVF inactivated combined oil vaccine is highly potent vaccine providing $80-100 \%$ protection of vaccinated pregnant ewes against type O, A and SAT2 of FMDV as shown in Table- 1 and also for the potency of RVF, the $\mathrm{ED}_{50}$ was 0.009 which is in aggrement with [28] and [29] who said that the permissible limit should not be more than 0.02 .

Also it was found that vaccinated pregnant ewes exhibited detectable antibody titers against all used viral antigens by the $1^{\text {st }}$ week post vaccination as determined by SNT and ELISA (Figures-2 and 3). These titers reached their peaks $(2.7,3 \& 2.65,3$ and 2.7, 3.15 by SNT and ELISA for FMD type O, A and SAT2 respectively) by $10^{\text {th }}$ week post vaccination while those of RVF (2.7 and 3.05 by SNT and ELISA respectively were recorded by the $12^{\text {th }}$ week post vaccination. These levels began to decrease gradually after that to record their lowest protective levels $(1.5,1.8 ; 1.5,1.8$ and 1.5, 1.75 by SNT and ELISA for FMD type O, A and SAT2 respectively) by the $32^{\text {nd }}$ week and those of RVF (1.5 and 1.75 by SNT and ELISA respectively) by the $34^{\text {th }}$ week post vaccination. These results are supported by [30] who reported that oil emulsion

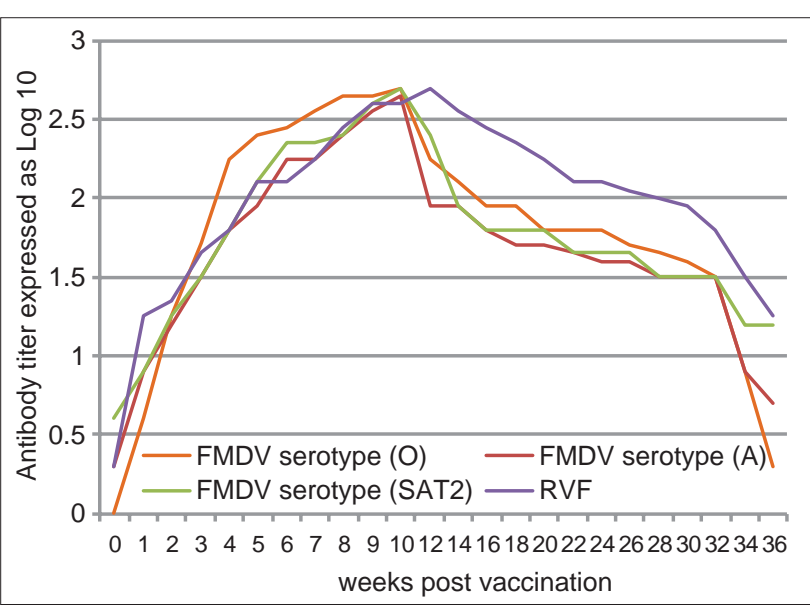

Figure-2: Mean Antibody titers in pregnant ewes vaccinated with combined Foot and Mouth disease/Rift Valley Fever vaccine estimated by serum neutralization test.

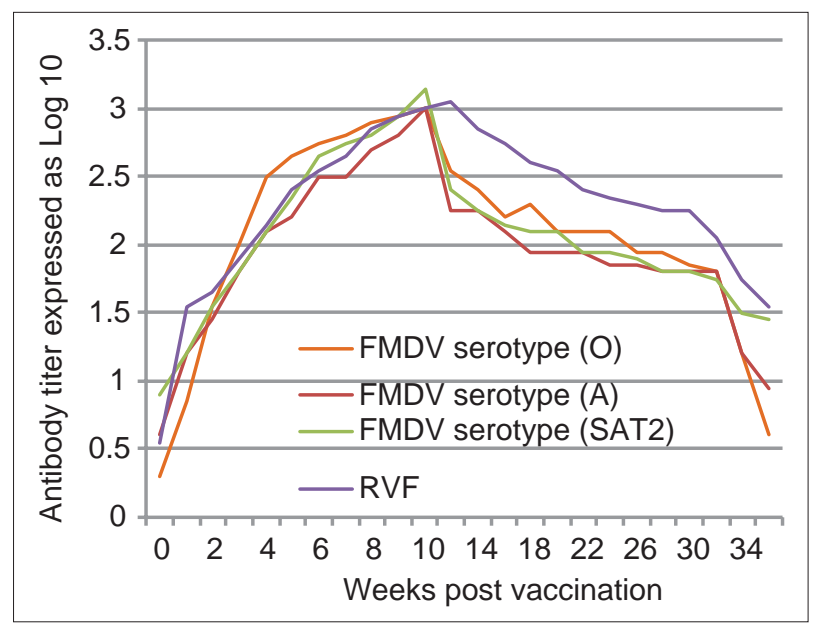

Figure-3: Mean antibody titers in pregnant ewes vaccinated with combined Foot and Mouth disease/Rift Valley Fever vaccine estimated by enzyme-linked immunosorbent assay.

FMD vaccine provides better results than alhydragel FMD vaccine. In addition the obtained results were in agreement with that supported previously [26] recorded that oil FMD vaccines gave a high and long duration immunity with oil FMD vaccine. Also the detected RVF antibodies came in parallel course with that obtained by [31]. In addition the present results agree with those of the earlier report [32] who prepared RVF/FMD combined vaccine which gave a high protection percentage against challenge with the virulent viruses, the earlier report [33] found that there were no significant difference between the immune response produced by the combined FMD/RVF vaccine and that produced by single vaccine against these diseases.

The present findings agree with the earlier report [34] who found that the Montanide ISA 206 oil vaccine can promote long immunity.

It was clear from Figures- 4 and 5 that lambs born to vaccinated ewes with the prepared combine FMD/RVF vaccine had sufficient maternal immunity against the included viral antigens transferred to them 
through their dam's colostrum. This immunity appear with good levels of specific FMD serotype $(\mathrm{O}, \mathrm{A}$ and SAT2) and RVF antibodies by the $1^{\text {st }}$ week of suckling recorded their peaks by the $6^{\text {th }}$ week then declined recorded the lowest protective levels against both antigens by the $12^{\text {th }}$ week of age. The present results were higher than that obtained by El-Shehawy et al. [35] who reported that the highest FMD antibody titer in serum of pregnant ewes was at $4^{\text {th }}$ week post vaccination, FMD

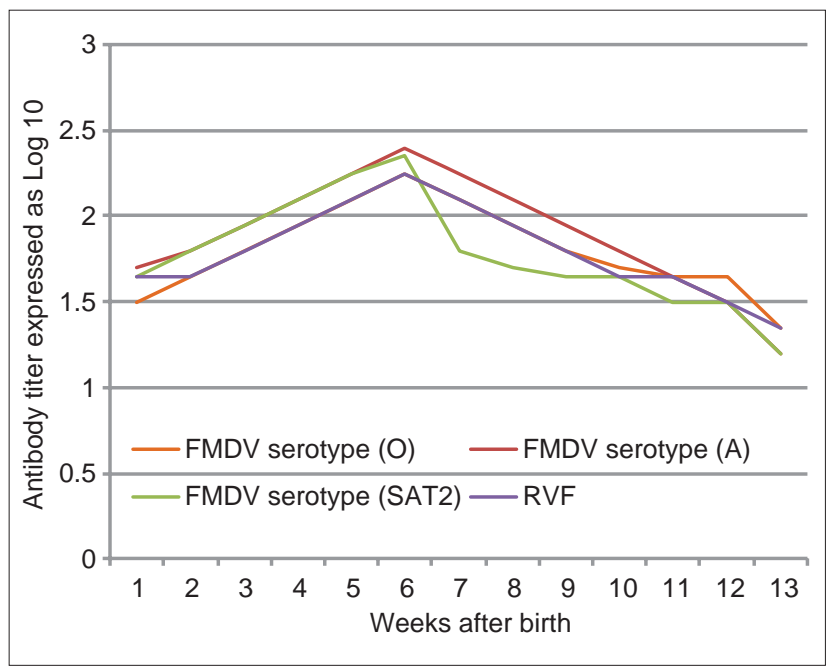

Figure-4: Mean antibody titers in newborn lambs from vaccinated ewes with combined Foot and Mouth disease/Rift Valley Fever vaccine estimated by serum neutralization test. antibody titer decreased in newborn at the $3^{\text {rd }}$ month of age to be non-protective level. Regarding RVF maternal immunity determination through the present work showed that it came in agreement with [36,37] who stated that RVF antibodies in newly born lambs sera remained at protective level for 3 month of age.

Also for complete studying of the maternal immunity, mean colostral antibodies were recorded as shown in Table- 2 that the mean colostral antibody titers were higher than serum of ewes at parturition, these results go in hand with the results obtained by

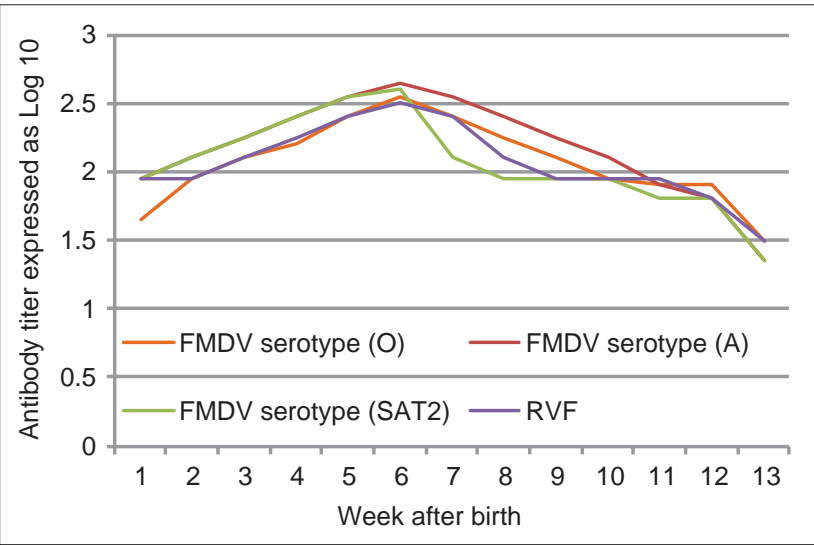

Figure-5: Mean antibody titers in newborn lambs from vaccinated ewes with combined Foot and Mouth disease/ Rift Valley Fever vaccine estimated by enzyme-linked immunosorbent assay.

Table-1: FMD lesions and protection percentage in sheep vaccinated with combined FMD/RVF and challenged against the three types of FMD virus.

\begin{tabular}{|c|c|c|c|c|c|c|c|c|c|}
\hline \multirow{3}{*}{$\begin{array}{l}\text { Animal } \\
\text { number }\end{array}$} & \multirow{3}{*}{$\begin{array}{l}\text { Animals } \\
\text { tested }\end{array}$} & \multicolumn{8}{|c|}{ Determined FMD lesions } \\
\hline & & \multicolumn{3}{|c|}{ Oral lesion } & \multicolumn{2}{|c|}{ Fore limb } & \multicolumn{2}{|c|}{ Hind limb } & \multirow{2}{*}{$\begin{array}{l}\text { Challenged } \\
\text { virus }\end{array}$} \\
\hline & & Tongue & Gum & Lip & $\mathbf{L}$ & $\mathbf{R}$ & $\mathbf{L}$ & $\mathbf{R}$ & \\
\hline 1 & $\ddot{0}$ & + & - & - & + & - & - & + & FMDV (O) \\
\hline 2 & $\subsetneq$ & - & + & - & - & - & - & - & FMDV (O) \\
\hline 3 & $\underset{\pi}{\pi}$ & - & - & + & - & - & - & - & FMDV (O) \\
\hline 4 & 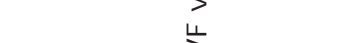 & - & + & - & - & - & - & - & FMDV (O) \\
\hline \multirow[t]{2}{*}{5} & $\gtrsim$ & - & - & - & - & - & - & - & FMDV (O) \\
\hline & $\overline{\bar{c}}$ & \multicolumn{8}{|c|}{ Protection $\%=80 \%$} \\
\hline 6 & $\sum_{4}^{L}$ & + & - & - & - & - & - & - & FMDV $(A)$ \\
\hline 7 & 0 & - & - & - & - & - & - & - & FMDV $(A)$ \\
\hline 8 & $\stackrel{\bar{\Phi}}{\subseteq}$ & - & + & - & - & - & - & - & $\operatorname{FMDV}(A)$ \\
\hline 9 & है & + & - & - & - & - & - & - & FMDV (A) \\
\hline \multirow[t]{2}{*}{10} & ริ & - & - & + & - & - & - & - & FMDV $(A)$ \\
\hline & c & \multicolumn{8}{|c|}{ Protection $\%=100 \%$} \\
\hline 11 & $\frac{1}{3}$ & + & - & - & - & - & - & - & FMDV (SAT2) \\
\hline 12 & $\frac{5}{0}$ & - & - & + & - & - & - & - & FMDV (SAT2) \\
\hline 13 & 过 & + & - & - & - & + & + & - & FMDV (SAT2) \\
\hline 14 & $\stackrel{\mathbb{N}}{\leftrightarrows}$ & - & + & - & - & - & - & - & FMDV (SAT2) \\
\hline \multirow[t]{2}{*}{15} & $\bar{U}$ & + & - & - & - & - & - & - & FMDV (SAT2) \\
\hline & $\stackrel{\pi}{>}$ & \multicolumn{8}{|c|}{ Protection $\%=80 \%$} \\
\hline 16 & Control positive (O) & + & + & - & + & + & + & + & FMDV (O) \\
\hline 17 & " & + & + & + & + & - & + & + & FMDV (O) \\
\hline 18 & Control positive (A) & + & + & + & - & + & + & + & FMDV $(A)$ \\
\hline 19 & c & + & + & + & + & + & + & + & FMDV (A) \\
\hline 20 & Control positive (SAT2) & + & - & + & + & + & + & + & FMDV (SAT2) \\
\hline 21 & com & - & + & - & + & + & + & - & FMDV (SAT2) \\
\hline 22 & Control negative & - & - & - & - & - & - & - & No challenge \\
\hline 23 & & - & - & - & - & - & - & - & No challenge \\
\hline
\end{tabular}

$\mathrm{L}=$ Left, $\mathrm{R}=$ Right, $\mathrm{FMD}=$ Foot and Mouth disease, $\mathrm{RVF}=$ Rift Valley fever, $\mathrm{FMDV}=$ Foot and Mouth disease virus 
Table-2: Mean FMD (O, A, SAT2) and RVF antibody titers in colostrums and serum of vaccinated ewes.

\begin{tabular}{|c|c|c|c|c|c|c|c|c|}
\hline \multirow{3}{*}{$\begin{array}{l}\text { Tested } \\
\text { material }\end{array}$} & \multicolumn{6}{|c|}{ FMD antibody titers } & \multicolumn{2}{|c|}{ RVF antibody titers } \\
\hline & \multicolumn{2}{|c|}{$\mathbf{0}$} & \multicolumn{2}{|c|}{$\mathbf{A}$} & \multicolumn{2}{|c|}{ SAT } & \multirow[t]{2}{*}{ SNT } & \multirow[t]{2}{*}{ ELISA } \\
\hline & SNT & ELISA & SNT & ELISA & SNT & ELISA & & \\
\hline Serum at parturition & 2.25 & 2.55 & 1.95 & 2.25 & 2.4 & 2.4 & 2.7 & 3.05 \\
\hline Colostrum $24 \mathrm{~h}$ post parturition & 2.7 & 2.95 & 2.4 & 2.7 & 2.8 & 2.95 & 3.1 & 3.25 \\
\hline
\end{tabular}

$\mathrm{FMD}=$ Foot and Mouth disease, RVF=Rift Valley fever, SNT=Serum neutralization test, ELISA=Enzyme-linked immunosorbent assay

the earlier report [35], who reported that FMD antibody level of colostrum was generally higher than that in serum of vaccinated dams.

In conclusion, vaccination of pregnant ewes at 2-3 months before parturition with FMD/RVF combined inactivated oil vaccine provide them with high antibody titers that could be transferred to their lambs through the colostrum and enable the newly born lambs to withstand any FMD and RVF infections for at least 3-4 months of age and depending on the previous results, the newly born lambs should be vaccinated at this age.

\section{Authors' Contributions}

Wael mossad has prepared the 3 serotypes of FMDV; perform the inactivation, purification, concentration of FMDV; aid in formulation of the combined vaccine; carry out the challenge protection percentage against FMDV serotypes; carry out the SNTand ELISA tests for antibody detection against FMD; wrote the manuscript and follow up the steps of publication.Eman soliman made the titration for RVFV; collect the serum and colostrum samples; carry out the evaluation of the vaccine including sterility, safety, potency of the vaccine for RVF; carry out the evaluation of humeral immunity of the combined vaccine against RVF; share in writing the manuscript.Mona elmanzalawy propagate the BHK monolayer cell line; prepare the RVFV; inactivate, purify and concentrate the RVFV; formulate the combined vaccine; innoculate pregnant ewes with the combined vaccine.

\section{Acknowledgments}

The authors are thankful to Prof. Dr. Sayed Zedan Director of VSVRI, Prof. Dr. Manal Awad Deputy of VSVRI and all members of FMD department specially Prof. Dr. Abu Bakr Aggour head of FMD department, VSVRI. Also thanks to Prof. Dr. Mohamed Hassan Khoudier, Prof. Dr. Khayrat Abdel Mageed Elian for reviewing this work. This work was funded by VSVRI, Abbasia, Cario, Egypt.

\section{Competing I nterests}

The authors declare that they have no competing interests.

\section{References}

1. Depa, P.M., Dimri, U., Sharma, M.C. and Tiwari, R. (2012) Update on epidemiology and control of foot and mouth disease - A menace to international trade and global animal enterprise. Vet. World, 5(11): 694-704.
2. Longjam, N., Deb, R., Sarmah, A.K., Tayo, T., Awachat, V.B. and Saxena, V.K. (2011) A brief review on diagnosis of footand-mouth disease of livestock: Conventional to molecular tools. Vet. Med. Int., 2011: 905768.

3. Aidaros, H.A. (2002) Regional status and approaches to control and eradication of FMD in the middle east and North Africa. Rev. Sci. Tech. Off. Int. Epizoot., 21(3): 451-8.

4. Farag, M.A., Aggour M.A. and Daoud, A.M. (2005) ELISA as a rapid method for detecting the correlation between the field isolates of foot and mouth disease and the current used vaccine strain in Egypt. Vet. Med. J., Giza., 53(4): 949-955.

5. Satya, P. (2009) Vaccination against foot-and-mouth disease virus: Strategies and effectiveness. Expert Rev. Vaccines, 8(3): 347-365.

6. Abed El- Rahman, A.O., Farag, M.A., El- Kilany, S., Ali, S.M. and Yazed, M.A. (2006) Isolation and identification of serotype $\mathrm{O}$ of foot and mouth disease virus from imported Bulls and its correlation to the current used vaccine strain O1/3/1993. Proc. $3^{\text {rd }}$ International Conference Veterinary Research Division. NRC, Cairo, Egypt, p91-100.

7. Shawky, M., Abd El-Aty, M., Fakry, H.M., Daoud, H.M., El-Sayed, I.E., Mossad, G.W., Rizk S.A., Abu-Elnaga, H., Mohamed, A.A., Abd El-Kreem A. and Farouk, E. M. (2013) Isolation and molecular characterization of foot and mouth disease SAT2 virus during outbreak 2012 in Egypt. J. Vet. Adv., 3(2): 60-68.

8. OIE. (2013) OIE Raift Valley Fever Factsheet. Accessed on 21-06-2013.

9. Mirabela, R., Richard, B., Michael, R.H., Stanley, J.W., Stefan, B., Willy, W. and Alexander, N.F. (2012) An assembly model of rift valley fever virus. Front Microbial, 3: 254.

10. WHO. (2012) Rift Valley Fever. Fact Sheet. No 207.

11. Hanafi, A.H., Fryauff, D.J., Saad, M.D., Soliman, A.K., Mohareb, E.W., Medhat, I., Zayed, A.B., Szumlas, D.E., Earhart, K.C., (2011) Virus isolation sand high population density implicate culex antennatus (Becker) (Diptera: Culicidae) as avector of rift valley fever virus during an outbreak in the Nile Delta of Egypt. Acta Trop., 119(2011): 119-124.

12. Summerpa, S.K., Clarence, J.P., James, L., Eric, M.M., Samuel, M., Kariuki Njenga, M., Robert, F.B., Clinton White, A.J.R. and Charles, H.K. (2010) Sever rift valley fever may present with a characteristic clinical syndrome. Am. J. Trop. Med. Hyg., 82(3): 371-375.

13. Lombard, M., Pastoret, P.P. and Moulin, A.M. (2007) A brief of vaccines and vaccination. Rev. Sci. Tech., 26(1): 29-48.

14. Sonia, A.M. (2003) Comparative studies on immune response of FMD and RVF combined vaccine containing OIMS 1313 oil adjuvant. M. V. Sc. Thesis, Microb. Faculty of Veterinary Medicine, Alexandria University, Egypt.

15. Ragaa, A.E (2007) Studies on production of oil inactivated rift valley fever vaccine using Montanide (IMS). M. Vet. Sic Thesis, (Infectious). Faculty of Veterinary Medicine. El Monufia University.

16. Postema, A.S., Myers, M.G. and Breiman, R.F. (2001) Challenges in the development, licensure, and use of combination vaccines. Clin, Infect. Dis., 33: S261-S266.

17. Falk, L.A., Arciniega, J., and McVittie, L. (2001) Manufacturing issues with combining different 
antigens: A regulatory perspective. Clin. Infect. Dis., 33: S351-S355.

18. Shabana, W. (2014) Preparation of combined oil vaccine against foot and mouth disease and rift valley fever in sheep. Phd. Faculty of Veterinary Medicine, Cairo University.

19. Xuan H., Li Y., Fang, H. and Zheng, C. (2011) Establishment of persistent infection with foot and mouth disease virus in BHK-21 cells. Virol. J., 8: 169.

20. Reed, L.J. and Muench, H. (1938) A simple method for estimating fifty percent (50\%) end points. Am. J. Hyg., 27: 493-497.

21. Health Protection Agency. (2009) Complement fixation tests. Issue no: 3 Issue date 11.12.09 Issued by: Standards unit, Department for Evaluations, standards and Training p1 of 23.

22. El Nimr, M.M. (1980) Studies on the inactivated vaccine against rift valley fever. Ph. D. Thesis (Microbiology). Faculty of Veterinary Medicine. Assuit University, Egypt.

23. Ismail, A.H., El-Mahdy, S.A., Mossad, W.G., Abd El-Krim, A.S., Abou El-Yazid, M. and Ali, S.M (2013) Optimization of the inactivation process of FMD virus serotype SAT-2 by binary ethyleneimine (BEI). J. Vet, Adv., 3(3): 117-124.

24. Code of Federal Regulation of USA. (1986) Animal and Animal Products 9\1986. Office of the Federal Register National Archives and Record Administration.

25. Randall, R., Binn, L.N. and Harrison, V.R. (1964) Immunisation against Rift Valley fever virus. Studies on the immunogenicity of lyophilised formalin inactivated vaccine. J. Immunol., 92: 293-299.

26. Ferreira, M.E.V. (1976) Microtitre neutralization test for the study of FMD antibodies. Bol. Cent. Pan. Am. Fiebre Aftosa, 21: 22-23.

27. Voller, A., Bidwell, D. and Bartlett, A. (1976) Microplate enzyme immunoassay for the immunodignosis of virus infection. Am. Soc. Microbiol., 506-512.

28. Gihan, K.M., Elian, K.A. and Eman, M.S. (1998): Studies on the keeping quality of binary inactivated Rift Valley fever Vaccine. Assuit Vet. J., 39, (77): 169-179.

29. Walker, J.S. (1975): Rift Valley Fever foreign animal disease. Their prevention, diagnosis and control. Committee of foreign animal disease of the United State. Animal Health Assoc., 209-221.

30. Barteling, S.J. and Vreswij, K.J. (1991) Development in foot and mouth disease vaccine. Vaccine, 9(2): 75-88.

31. Mona, F.M. (2005) Trial for production of highly immunized oily inactivated RVFV vaccine. M. Vet. Sci. thesis (Microbiology). Fac. Vet. Med. Banha University, Egypt.

32. Gihan, K.M. (1990) Studies on rift valley fever among animals in Egypt. Ph. D Thesis, Infectious Disease. Faculty of Veterinary Medicine, Zagazig University, Egypt.

33. Daoud, A.M., El-Deghaidy, W., Shawky, M., Hassan, K.Z. and Taha, M.M. (2001) Trial for preparation and evaluation of inactivated alhydragel combined vaccine for FMD and RVF. Beni-Suef Vet. Med. J., XI(2): 599-607.

34. El-Sayed, E., Mossad, W., Ali, S.M. and Shawky, M. (2012) Studies on the duration of immunity induced in cattle after natural FMD infection and post vaccination with bivalent oil vaccine. Vet. World, 5(10): 603-608.

35. El-Shehawy, L.E., Tallat, A.A. and EL-Watany, H.M. (2004) Some studies on maternal immunity of FMD in sheep. J. Egypt. Vet. Med. Assoc. 64(3): 2004.

36. ElSayed, N.E. (2013) Recent approach for development of the oil inactivated rift valley fever vaccine using new surfactant blend. M. V. Sc. Thesis Virology. Faculty of Veterinary Medicine, Benha Univerisity.

37. El-Sawalhy A.A., Hamoda F.K., Elian K.A., and Gehan M.K. (1997) Clinical and laboratory studies on Rift Valley Fever vaccines in sheep. J. Egypt Vet. Ass; 57(1): 363-386. 